\title{
Monitoring of water bodies as a technology for sustainable development
}

\author{
Natalia Lazareva $^{1 *}$ \\ ${ }^{1}$ International Banking Institute, Nevsky prospect, 60, 191011 St. Petersburg, Russia
}

\begin{abstract}
To achieve the goals of sustainable development, environmental monitoring of water bodies is considered as a modern technology for sustainable development in the field of clean water and a tool for the rational use of water resources. The works of the participants of the Baltic scientific and engineering competition on environmental monitoring, assessment of the ecological state of water bodies are analyzed. Biological purification of water bodies is not unlimited. When the intensity of the intake of pollutants exceeds the sanitary capabilities of water bodies, the ecosystem is destroyed. A set of measures for the environmental safety of river water is outlined. Reducing pollution, refusal from unauthorized dumping of waste, untreated wastewater are considered as means of improving water quality. Based on the review of competitive projects, priority measures were proposed to ensure the sustainable development of territories, including the conduct of massive information and educational projects, the implementation of internal control of the cleanliness of coastal zones of water bodies, and continuous environmental monitoring of water bodies.
\end{abstract}

\section{Introduction}

Environmental monitoring is a tool for achieving sustainable development goals. The availability and high quality of drinking water determine the health and life expectancy of the population of the territory. Surface sources are the main sources of water supply along with underground sources. Despite the fact that water resources are renewable, their rational use is a priority of our time. Human activities should be reasonable and aimed at preserving aquatic ecosystems, which ensures the preservation of environmental safety. The ecological monitoring of water bodies carried out for the conservation of water resources is aimed at the rational use of water resources. Indicators of achieving the goals of sustainable development of territories in the field of clean water are a significant proportion:

1. the population that uses the water supply, observing safety requirements

2. safely treated waste water;

3. reservoirs of good water quality;

4. transboundary water basins with water use cooperation;

5. administrative bodies involved in water resources management.

To assess the achievement of the goals, the dynamics of changes in the water use efficiency and the area of ecosystems associated with water are also analyzed; the level of

\footnotetext{
* Corresponding author: Lazarevan69@mail.ru
} 
water load is calculated: the percentage of fresh water intake to the available fresh water resources; the degree of implementation of integrated water resources management is determined (from 0 to 100). The main measures for the rational use of water resources have demanded directions for practical implementation (Table 1).

Table 1. Rational use of water resources

\begin{tabular}{|l|l|}
\hline Measures & Directions for the practical implementation of measures \\
\hline $\begin{array}{l}\text { Preservation } \\
\text { of natural } \\
\text { habitat }\end{array}$ & $\begin{array}{l}\text { a decrease in human consumption of water; } \\
\text { preservation of the natural aquatic environment important for local flora and fauna; } \\
\text { increase in total watercourse }\end{array}$ \\
\hline Renewability & $\begin{array}{l}\text { ensuring the availability of water resources for future generations; } \\
\text { non-exceeding the natural coefficient of water substitution with fresh water intake }\end{array}$ \\
\hline $\begin{array}{l}\text { enhancing } \\
\text { environmental } \\
\text { liability }\end{array}$ & $\begin{array}{l}\text { application of measures of responsibility to enterprises; } \\
\text { introduction of measures of responsibility of the population for the condition and } \\
\text { protection from pollution and depletion of water resources }\end{array}$ \\
\hline $\begin{array}{l}\text { Restoration of } \\
\text { water bodies }\end{array}$ & $\begin{array}{l}\text { restoration and conservation of water bodies; } \\
\text { ensuring environmentally friendly living conditions for } \\
\text { population; } \\
\text { dynamics of growth of the specific gravity of safely treated wastewater }\end{array}$ \\
\hline $\begin{array}{l}\text { Institutional } \\
\text { regulation }\end{array}$ & $\begin{array}{l}\text { legislative enforcement of the rational use of water resources; } \\
\text { professional regulation of the rational use of water resources with methodological } \\
\text { support }\end{array}$ \\
\hline $\begin{array}{l}\text { Development } \\
\text { of the water } \\
\text { management } \\
\text { complex }\end{array}$ & $\begin{array}{l}\text { improvement of drinking water preparation technology; } \\
\text { modernization of wastewater treatment technology; } \\
\text { reconstruction and new construction of water supply facilities; } \\
\text { introduction of new technologies for water purification. }\end{array}$ \\
\hline
\end{tabular}

In February-April 2021, the Baltic Science and Engineering Competition vk.com/balticsef was held in St. Petersburg, where the projects aimed at studying the state of water and environmental monitoring of water bodies were presented:

-Environmental monitoring of the lake Kustarevsky Demsky administrative district of Ufa (I. Zyablitsky);

-Assessment of the ecological state of the Belaya River in the city of Meleuz by zoobenthos for the period 2019-2020. (K. Valeeva);

-Study of biodiversity of the State Natural Reserve of Regional Significance "Lake Lenevo" (P. Prokasheva).

The participants of the competition are Russian schoolchildren, which confirms their growing scientific acceleration. The author of the article was a member of the jury, which resulted in the need to review the problems and prospects of environmental monitoring of water bodies.

The problems raised by the participants of the competition are especially relevant in the context of ensuring sustainable development of territories while achieving the global goals of $S D G s$, in particular clean water and sanitation. And that is the main thing, since in the modern conditions of hyper digital development, a reassessment of relations is necessary. The vector of further development should be a reasonable attitude to the environment of everyone, careful attitude to water resources, excluding their barbaric consumer ruinous use. The garbage left near water bodies after a mass visit by humans makes us not to talk again about the right to clean water and an ecologically clean environment, but to outline the priority measures to ensure the sustainable development of territories with clean water. These measures are the subject of research in this article. 
Environmental monitoring of the lake of the Kustarevsky Demskiy administrative district of Ufa, the "EcoPost" project was carried out within the framework of the federal project "Environmental Patrol in the Republic of Bashkortostan", which was started in 2008 by the pupils of the "Rostok" Economic and Social Center. The Demsky administrative district of Ufa includes only two water bodies, one of which is Kustarevskoye Lake, therefore, with an increasing anthropogenic influence due to the intensification of agriculture, recreational use in the territories of national and natural parks, the rational use of the lake ecosystem requires continuous environmental monitoring.

"The symmetry of goals provides a clear framework for developing a comprehensive policy to ensure universal accessibility, quality, efficiency in the use of natural resources, stimulate cooperation and technology transfer" [1].

The introduction of new technologies "can only be achieved in harmony with the established behavioral attitudes of residents" [2].

\section{Materials and Methods}

Aquatic plants remove impurities from water. The latter enter water bodies more often with surface runoff. The environmental monitoring of Kustarevskoye Lake by Zyablitsky showed that lake reeds and narrow-leaved cattails absorb phosphorus and nitrogen from wastewater, accelerate the oxidation of oil products in the reservoir. The length of Kustarevskoe Lake is more than $4 \mathrm{~km}$ with a depth of up to $2.5 \mathrm{~m}$. During this monitoring, special attention was paid to saprobity, as the degree of pollution of watercourses with organic substances, which made it possible to distinguish between pure polysaprobic, $\beta, \alpha$-mesosaprobic with an average degree of pollution and dirty polysaprobic watercourses. It was the dynamics of saprobity in macrophytes and invertebrates that was the subject of the study of the ecological monitoring of Lake Kustarevskoe, which showed the following:

- The conditional division of the reservoir into four parts and the laying in each part of the test site for the morphological and geobotanical description of the reservoir made it possible to classify it as a higher aquatic vegetation, calculate the saprobity index for each part, and showed that at the place of the fuel oil spill, the lake became $\alpha$ - mesosaprobic;

- aquatic invertebrates live in water bodies of a certain degree of pollution, organisms of a medium degree of saprobity - dragonfly larvae and molluses appeared in the lake at the end of August;

- determination of the parameters of atmospheric air and water, carried out using digital sensors, showed the presence of household waste in the beach area;

- on a sunny day, carbon dioxide is predominantly more in the green zone, since the process of photosynthesis is actively going on, compared to the railway zone, while the oxygen content is higher than normal; the content of hydrocarbons was estimated by the presence of an iridescent film on the surface of the water, which was absent by the end of August;

- analysis of the floristic characteristics of coastal and aquatic vegetation showed the disappearance of some macrophytes.

Valeeva's assessment of the ecological state of the Belaya River in the city of Meleuz in terms of zoobenthos for the period 2019-2020 showed that river water pollution was negatively affected by:

- nonpoint discharges, liquid waste;

- wash-offs from agricultural facilities and settlements;

- pollution by industrial hub, oil production facilities;

- industrial and domestic wastewater;

- deposition of pollutants from the atmosphere. 
This influence resulted in the quality of the baseline water being assessed as "very polluted". The zoobenthos of the river in the area of the Meleuz town is insufficiently studied. The conducted studies of the chemical composition of water in the absence of biological monitoring of the water body served as the basis for assessing the pollution of the water body. Valeeva investigated that the composition of bottom sediments depends on the speed of the river flow, the nature of the terrain. The bottom dwellers have an important influence on the process of biological self-purification of water bodies. Carried out by Valeeva collection, processing and analysis of zoobenthos from six points showed that the water quality of the river Belaya in the section downstream of the town of Meleuz was affected by waste water from the city water utility. Zoobenthos is very diverse in October. As the water pollution increases, the taxonomic structure of the biocenosis becomes simpler. The disappearance of different groups of animals from the reservoir is characteristic as the pollution grows.

In the study of the Prokasheva area of the natural reserve of regional significance "Lake Lenevo", local monitoring and a route method were used, which made it possible to note changes in the number and species diversity of vegetation, as well as to compile a list of lichen and fungi species. Similar to the conclusions of other participants in the competition, Prokasheva identified the main sources of water pollution: industrial and domestic wastewater. It is she who considers bottom sediments of reservoirs as an indicator for identifying the intensity and composition of technogenic pollution, which made it possible to evaluate the effectiveness of using the RU170251 floating filter nozzle for cleaning the tested wastewater of a particular sanatorium. The methods of analysis, comparison, experiment used by her made it possible to draw the following conclusion:

- floating filtering nozzle RU170251 allows with high efficiency and productivity to purify wastewater from mechanical impurities, bio-utilize organic matter, eliminate specific odors, reduce chemical indicators;

- after the closure of the sanatorium due to covid period, the catalase activity of coastal bottom sediments is at the level of a medium-rich degree of soil enrichment in all sampling sites.

A global problem is the shortage of clean water. Internal control of sustainable development of territories is aimed at solving this problem while achieving a similar goal. Improving water quality by reducing industrial and household pollution, eliminating unauthorized waste disposal, reducing the proportion of untreated wastewater and increasing the scale of recycling, safe multiple reuse of wastewater is a priority for the sustainable development of each territory.

\section{Results and Discussion}

An obvious massive tool for internal control of sustainable development of territories is environmental monitoring of water bodies, which makes it possible to assess the safety of river water.

Environmental safety of river water can be achieved through a set of measures:

- expansion of construction of treatment facilities;

- decrease in the concentration of pollutants in water [3];

- remote monitoring of SBR wastewater treatment based on MCGS [4];

- determination of the degradation characteristics of the main pollutants of river mouths [5];

- an inventory of emissions from ships based on data from the automatic identification system (AIS), scheme of internal emission control areas (DECA) [6]; 
- elimination of bad living habits of residents, gaps in state supervision [7];

- improvement of the technology of efficient wastewater treatment of production facilities [8].

\section{Conclusions}

Based on the review of the competition projects, the following priority measures have been developed to ensure the sustainable development of territories:

1. conducting mass educational work through social networks, mass lecture courses on ensuring the rational use of water and respect for water resources;

2. implementation of continuous monitoring of the cleanliness of coastal areas of water bodies;

3. creation of tourist and recreational zones for the development of educational tourism;

4. continuous environmental monitoring of water bodies;

5. educational online excursions www.youtube.com/watch? $\mathrm{v}=\mathrm{BjrcGzG} 35 \mathrm{SM}$ for mass viewing.

\section{Acknowledgements}

The article includes an overview of the competitive works of the participants of the XVII Baltic Science and Engineering Competition. The author expresses gratitude to the organizers and participants of the Competition for the research that has confirmed the importance of monitoring water bodies for ensuring sustainable development of territories.

\section{References}

1. D. Sklarew, J. Sklarew, Integrated Water-Energy Policy for Sustainable Development (2018)

2. Z. Mingaleva, et al. Waste Management in Green and Smart Cities: A Case Study of Russia (2020)

3. LI Jiatong, et al., IOP Conf. Cep .: Earth Environ. Sci., 651, 042040 (2021)

4. Hu Zhihao, et al IOP Conf. Ser.: Earth Environ. Sci., 651,042049 (2021)

5. He Chengqi, et al. IOP Conf. Cep .: Earth Environ. Sci., 651, 042048 (2021)

6. Qin Cuihong, et al IOP Conf. Ser.: Earth Environ. Sci., 651, 042054 (2021)

7. Yu Xialei, et al IOP Conf. Ser.: Earth Environ. Sci., 651, 042056 (2021)

8. Ni Tingting, et al., 2021 IOP Conf. Cep .: Earth Environ. Sci., 651, 042065 (2021) 